\title{
Endoscopic bariatrics: current therapies and future directions
}

\author{
Debashis Reja ${ }^{1}$, Clark Zhang ${ }^{1}$, Avik Sarkar $^{2}$ \\ ${ }^{1}$ Division of Internal Medicine, Department of Medicine, Robert Wood Johnson Medical Center, New Brunswick, New Jersey, USA; ${ }^{2}$ Division of \\ Gastroenterology, Department of Medicine, Robert Wood Johnson Medical Center, New Brunswick, New Jersey, USA \\ Contributions: (I) Conception and design: D Reja, A Sarkar; (II) Administrative support: None; (III) Provision of study materials or patients: None; \\ (IV) Collection and assembly of data: None; (V) Data analysis and interpretation: None; (VI) Manuscript writing: All authors; (VII) Final approval of \\ manuscript: All authors. \\ Correspondence to: Avik Sarkar, MD. Division of Gastroenterology, Department of Medicine, Robert Wood Johnson Medical Center, New Brunswick, \\ New Jersey, USA. Email: avik.sarkar@rutgers.edu.
}

\begin{abstract}
Endoscopic bariatric therapies (EBTs) are endoscopic procedures indicated for weight loss in the obese population. They are shown to be safe and effective for patients who do not quality for bariatric surgery. There are currently no randomized controlled studies comparing bariatric surgery with EBTs. However, EBTs are more cost effective and have fewer complications. This review will examine currently available EBTs with published data.

Keywords: Bariatric; obesity; endoscopy; intragastric balloon (IGB); transpyloric shuttle (TPS); aspiration; transoral outlet reduction (TORe); primary obesity surgery endoluminal (POSE); endobarrier; duodenal-jejunal bypass liner; gastro-duodeno-jejunal bypass sleeve; duodenal mucosal resurfacing; endoscopic sleeve gastroplasty; endobariatric
\end{abstract}

Received: 14 November 2019; Accepted: 23 March 2020; Published: 25 April 2022.

doi: $10.21037 / \operatorname{tgh} .2020 .03 .09$

View this article at: http://dx.doi.org/10.21037/tgh.2020.03.09

\section{Introduction}

Obesity has become a worldwide epidemic and is associated with increased all-cause and cardiovascular mortality, as well as diabetes, hypertension, and hyperlipidemia (1). Lifestyle modifications serve as the foundation of treatment, comprised of diet, exercise, and behavioral changes. Patients often find it difficult to maintain a healthy weight with lifestyle interventions alone.

Several pharmacological agents are FDA approved for weight loss. They include Orlistat, Phentermine, Phentermine/Topiramate, Locaserin, Naltrexone/ Bupropion, and Liraglutide. They are approved for patients with BMI $>27 \mathrm{~kg} / \mathrm{m}^{2}$ with one obesity complication or BMI $>30 \mathrm{~kg} / \mathrm{m}^{2}$. They are shown to have modest benefits, with studies calculating 3-7\% total body weight loss (TBWL) at 1 year, and are generally not well tolerated (2).

Bariatric surgery is indicated for patients with $\mathrm{BMI}>$ $40 \mathrm{~kg} / \mathrm{m}^{2}$ or BMI $>35 \mathrm{~kg} / \mathrm{m}^{2}$ with one comorbidity. Roux-
en-Y gastric bypass and sleeve gastrectomy are the most common procedures. Excess weight loss (EWL) at 12 months was demonstrated to be $63-72 \%$ and $52-70 \%$, respectively (3). However, barriers to surgery such as low referral rates, limited access, and cost, result in $1 \%$ to $2 \%$ of eligible patients ever getting the procedure (4). Bariatric surgery also poses major adverse events such as anastomotic ulceration, stenosis, fistulas, intestinal obstruction, and surgical leaks (5). Complication rates range between $7-10 \%$, and the likelihood of major complications is $4 \%(6)$.

In this review, we discuss novel endoscopic bariatric procedures that can be used for patients who fail lifestyle or pharmacological therapies, and for patient not eligible for or not interested in a surgical procedure. This review focuses on mechanisms, as well as efficacy and safety data. The EBT are separated into gastric interventions and small bowel interventions (3,7-14). 

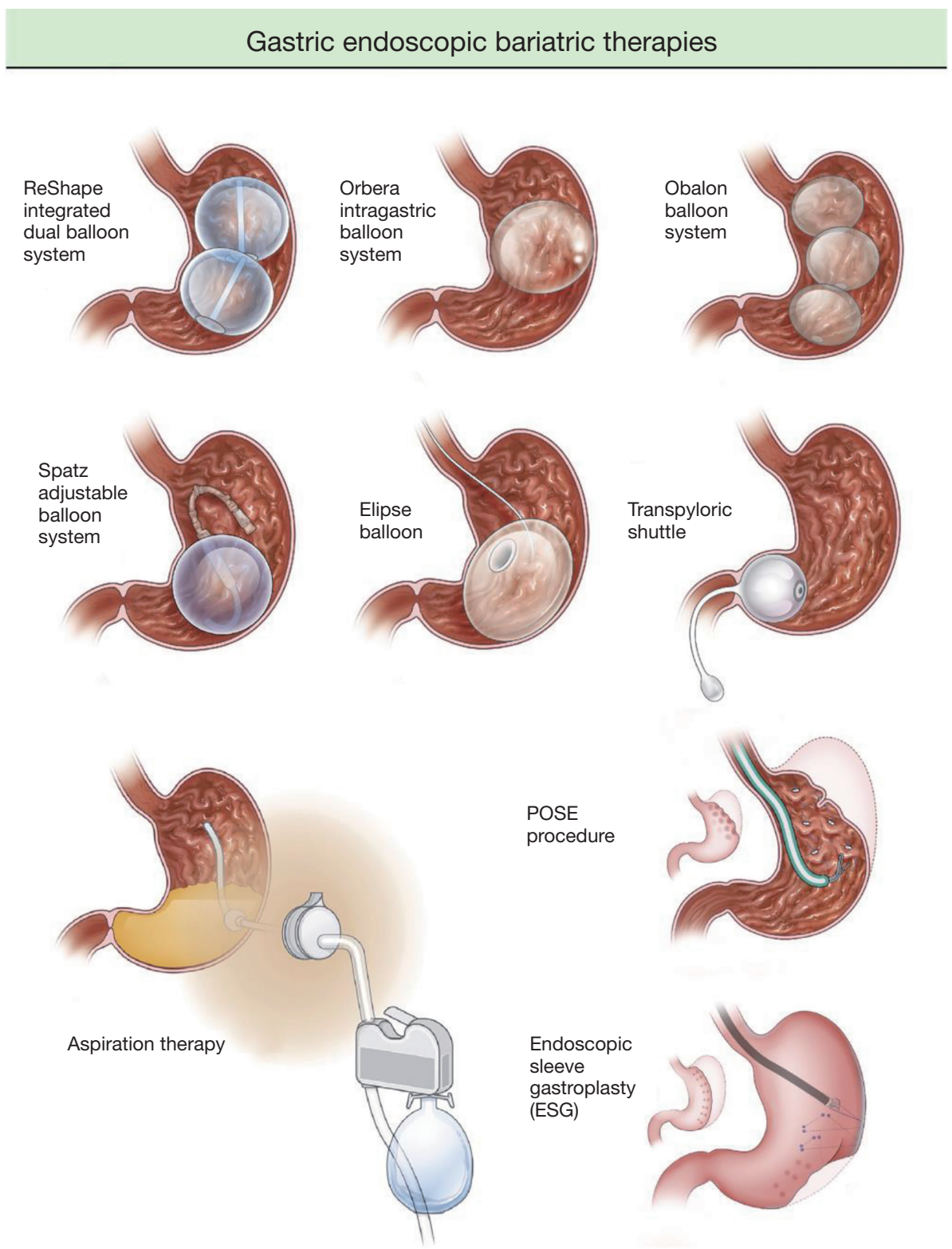

Figure 1 Gastric endoscopic bariatric therapies (17). POSE, primary obesity surgery endoluminal.

\section{Gastric interventions}

\section{Intragastric balloons (IGBs)}

IGBs function by taking up space in the stomach, thereby leading to an early sense of fullness and delayed gastric motility. They also work by altering gastric hormones such as ghrelin and cholecystokinin $(15,16)$. The value of IGBs in relation to gastric bypass surgery is that while they may not lead to as significant weight loss reduction, they are indicated at a lower body mass index (BMI) threshold of
$30-40 \mathrm{~kg} / \mathrm{m}^{2}$ and have overall fewer side effects. There are currently three FDA approved IGBs-Orbera, ReShape, and Obalon—and two pending FDA approval-Elipse and Spatz. The three FDA approved IGBs all have a 6-month implantation time. The ReShape, Orbera, and Spatz balloons are endoscopically placed, while the Obalon and Elipse balloons are swallowed in a capsule. Randomized control trials have been promising in showing that IGBs lead to significant weight reduction compared to control groups (Figure 1, Table 1). 
Table 1 Intragastric balloons

\begin{tabular}{|c|c|c|c|c|c|c|}
\hline $\begin{array}{l}\text { Treatment } \\
\text { or device }\end{array}$ & Type & FDA approval & $\begin{array}{l}\text { Maximum } \\
\text { implantation time }\end{array}$ & $\begin{array}{l}\text { \%TBWL at } \\
\text { balloon removal }\end{array}$ & $\begin{array}{l}\% \text { TBWL at } \\
12 \text { months }\end{array}$ & Adverse events \\
\hline $\begin{array}{l}\text { ReShape } \\
\text { Duo }\end{array}$ & $\begin{array}{l}\text { Balloon } \\
\text { (double) }\end{array}$ & $\begin{array}{l}\text { BMI 30-40 with } 1 \text { obesity } \\
\text { related comorbidity, age 22-60 }\end{array}$ & 6 months & $6.8-11.4 \%$ & & $\begin{array}{l}\text { Gastric ulceration }-10 \% \text {, } \\
\text { balloon deflations } 6 \%\end{array}$ \\
\hline Orbera & $\begin{array}{l}\text { Balloon } \\
\text { (single) }\end{array}$ & $\begin{array}{l}\text { BMI 30-40 with } 1 \text { obesity } \\
\text { related comorbidity, age 22-60 }\end{array}$ & 6 months & $10.2-11.8 \%$ & $7.60 \%$ & $\begin{array}{l}\text { Early removal } 7 \% \text {, } \\
\text { migration } 1.4 \%\end{array}$ \\
\hline Spatz ABS & $\begin{array}{c}\text { Balloon } \\
\text { (adjustable) }\end{array}$ & No & 12 months & $14.9 \%$ & $\mathrm{~N} / \mathrm{A}$ & Early removal 7\% \\
\hline Elipse Balloon & $\begin{array}{c}\text { Balloon } \\
\text { (single) }\end{array}$ & No & 4 months & $10.0-15.1 \%$ & $5.90 \%$ & Nausea/vomiting \\
\hline
\end{tabular}

BMI, body mass index; TBWL, total body weight loss.

Table 2 Most common adverse events IGB

\begin{tabular}{lccc}
\hline Adverse event & ReShape Duo (\%) & Orbera (\%) & Obalon (\%) \\
\hline Vomiting & 86.7 & 86.8 & 17.3 \\
Nausea & 61.0 & 75.6 & 56.0 \\
Abdominal pain & 54.5 & 57.5 & 72.6 \\
Gastric ulcer & 35.2 & 0.0 & 0.9 \\
Dyspepsia & 17.8 & 21.3 & 16.9 \\
\hline
\end{tabular}

IGB, intragastric balloon.

\section{Orbera}

The Orbera Intragastric Balloon System (Apollo Endosurgery, Austin, TX) is a single balloon that is endoscopically placed and filled with saline. The balloon is left in place for 6 months, then endoscopically removed. The Orbera is the most commonly used IGB in the world, with close to 300,000 devices already distributed (18). A meta-analysis of 17 studies totaling 1,638 patients showed TBWL of $11.3 \%$ and EWL of $25.4 \%$ at 12 months (19). This balloon system demonstrated the greatest amount of weight loss compared to the other two FDA approved IGBs, though this is possibly related to study design (20). The majority of complications were minor, including complaints of nausea, vomiting, and abdominal pain. Up to $23.3 \%$ of patients experienced nausea and vomiting and $19.9 \%$ experienced abdominal pain (21). Many of these complaints gradually decreased over time. More serious complications such as obstruction or perforation did occur, but these incidences were rare and happened in many patients with prior history of gastric surgery (19) (Table 2).

\section{ReShape}

The ReShape Duo Integrated Dual Balloon System (Reshape Medical, San Clemente, CA) consists of two balloons that are endoscopically placed and filled with saline. It is removed at 6 months. The REDUCE Pivotal Trial was a randomized sham-controlled trial that followed 326 patients for two years and compared the dual balloon system (DBS) to sham endoscopy, with both groups also having diet and exercise interventions. The study found $25.1 \%$ EWL in the DBS group compared to $11.3 \%$ in the sham group (7). The serious adverse event (SAE) rate was $7.5 \%$, but $75 \%$ of these events were self-limiting symptoms such as nausea, vomiting, and abdominal pain (22).

Of note, a recent safety review of Orbera and ReShape showed that from 2006 to 2017, these two IGBs were associated with 33 deaths, with Orbera specifically involved in 27 of them (23). From 2016 to 2018, 12 deaths worldwide have been associated with Orbera and ReShape, some of which may have been directly related to balloon placement or removal. The FDA continues to monitor closely and 
has issued a safety alert warning for healthcare providers and patients with information about possible death with these devices. The FDA recommends that healthcare providers instruct patients of potentially life-threatening complications, monitor patients closely, and report any adverse events (24).

\section{Obalon}

The Obalon Balloon System (Obalon Therapeutics, Carlsbad, CA) is also designed to be in place for 6 months, but it differs from Orbera and ReShape in that it is swallowed rather than endoscopically placed. Obalon consists of three balloons that are filled with gas rather than saline, with balloons placed at month 0 , month 1 , and month 3. In the SMART trial, 387 patients with a BMI between 30 and $40 \mathrm{~kg} / \mathrm{m}^{2}$ were followed for two years as part of a double-blind, randomized sham-controlled trial. It was shown that patients who swallowed the gas balloons had $7.1 \%$ TBWL compared to $3.6 \%$ in sham controls, with a mean difference of $3.5 \%$. The responder rate, which was defined as at least $5 \%$ TBWL at the 2-year mark, was $66.7 \%$ in the Obalon group (11). The most common side effects were nausea, vomiting, and abdominal pain, with rare incidences of balloon deflations. Overall, the SAE rates were lowest in Obalon compared to that of Orbera or ReShape (17).

\section{Spatz (not FDA approved)}

The Spatz Adjustable Balloon System is a silicone sphere with an attached inflation catheter that allows for adjustment of filling volumes. This is to accommodate changes in weight loss goals or to help better control side effects. It is pending FDA approval and was designed to be endoscopically removed at 1 year, which is an effort to address premature device removal in the current FDA approved IGBs. Preliminary studies have shown promising results. A German study tracked 110 patients with BMI greater than $27 \mathrm{~kg} / \mathrm{m}^{2}$ and demonstrated an average EWL and waist-girth reduction of $16.0 \mathrm{~kg}$ and $11.3 \mathrm{~cm}$, respectively, at 12 months with Spatz; no serious complications were noted (25). A prospective study of patients who underwent Spatz from 2012 to 2014 showed a median weight loss of about $20 \mathrm{~kg}$ at 12 months, without any severe complications (26). Another two prospective studies reported $45-48 \%$ EWL at 12 months $(27,28)$. A recent FDA trial demonstrated $14.9 \%$ TBWL at balloon removal.

\section{Elipse (not FDA approved)}

The Elipse Balloon is another IGB pending FDA approval, and similar to Obalon, it was designed to be swallowed. It is unique in that it does not require endoscopy for removal. The Elipse is a single, fluid-filled balloon that remains in the stomach for 4 months, after which it self-degrades and passes in the stool. One multicenter prospective study of 135 patients showed a mean weight decrease and mean TBWL of $13 \mathrm{~kg}$ and $15.1 \%$, respectively, at 4 months. Side effects included nausea reported by all patients on the first day of insertion and diarrhea and colicky abdominal pain after balloon deflation. Early vomiting, deflation, and removal of the balloon were also noted, but these all occurred in less than $3 \%$ of patients. One patient had small bowel obstruction that was resolved with laparoscopic enterotomy (29). Another prospective study of 51 patients demonstrated average total weight loss of $8.8 \mathrm{~kg}$ and TBWL of $10.4 \%$ at the 4-month mark. Symptoms during insertion such abdominal pain and nausea and vomiting were profound, with an average severity of 9.5 out of 10 during the first three days. However, a majority of these symptoms resolved with appropriate medical therapy. Upon removal of the balloon, diarrhea and abdominal discomfort were the most common side effects, but these were less severe and mainly resolved on their own (30).

\section{IGBs in combination with bariatric surgery}

While IGBs have proven to be effective at reducing weight alone, there are also studies that emphasize the important role of IGBs in conjunction with bariatric surgery to achieve long-term weight loss goals. In one study that followed 271 patients over the course of 60 months, it was found that IGB alone led to $9.04 \% \mathrm{EWL}$, whereas IGB plus gastric banding led to $32.9 \%$ EWL and IGB plus staple procedure led to $52.8 \%$ EWL (31). Another study was carried out in Turkey that followed 25 patients who underwent BioEnterics IGB procedure. It showed that while there was initially $46.9 \%$ EWL at six months, almost all the patients regained the weight back at the next 6-month follow up after balloon removal (32). The authors of this study concluded that IGB therapy alone is not particularly 


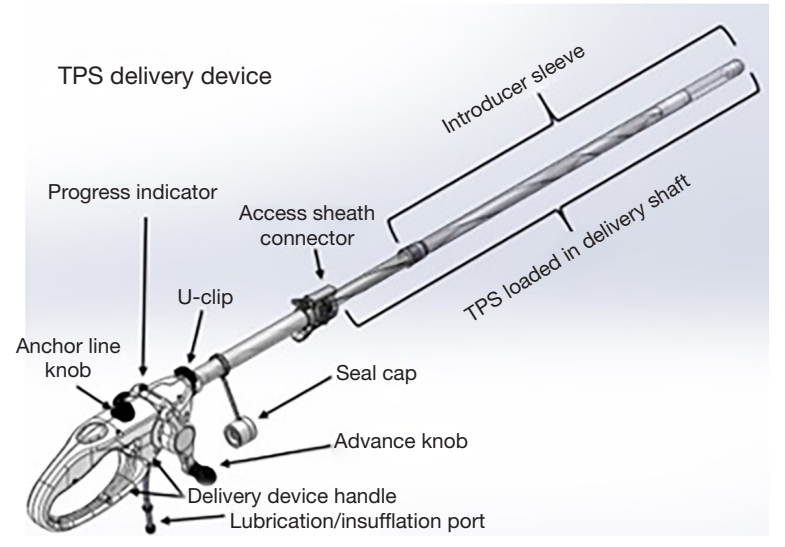

Figure 2 Transpyloric shuttle (36). TPS, transpyloric shuttle.

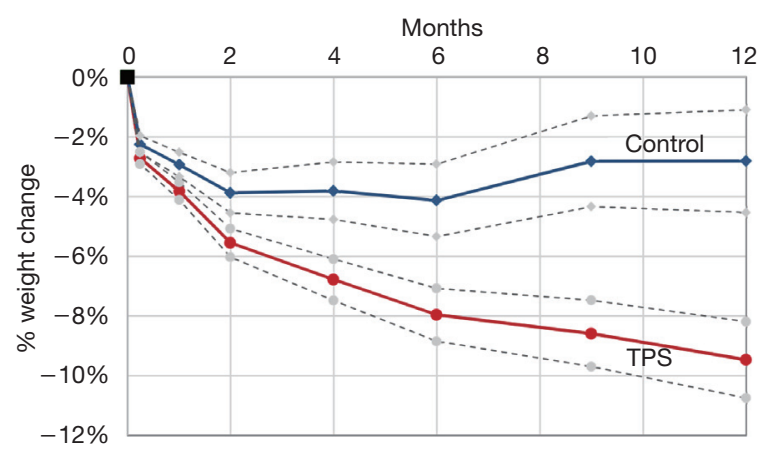

Figure 3 TPS weight loss vs. control (37). TPS, transpyloric shuttle.

effective at long-term weight loss, but they may be used as a bridge to surgery to help improve morbidity and mortality.

\section{Transpyloric shuttle (TPS)}

The TPS is an FDA-approved device that consists of a large silicone ball that is connected to a smaller one via a tether. It is delivered into the stomach, where the large ball floats around freely and the smaller weight traverses the pylorus and rests in the proximal duodenum. When food is ingested, peristalsis shifts the larger ball onto the pylorus, causing a temporary obstruction that delays gastric emptying. The TPS is designed to stay in the stomach for 12 months. It is indicated in patients with a BMI between $35-40 \mathrm{~kg} / \mathrm{m}^{2}$ or a BMI between $30-34.9 \mathrm{~kg} / \mathrm{m}^{2}$ with an associated medical condition (such as diabetes) who have been otherwise unresponsive to traditional therapies (33). According to the pivotal trial that led to FDA approval of the device, patients treated with TPS had about $9.3 \%$
TBWL compared to $2.8 \%$ in sham controls at 12 months; it was also noted that $66.8 \%$ of TPS patients achieved at least $5 \%$ TBWL at the 12-month mark (34). The most common side effects were nausea, upper abdominal pain, vomiting, and dyspepsia, with a majority of these symptoms rated as mild to moderate. Another small study of 20 patients showed that there was $15 \%$ TBWL at 6 months with the TPS (35) (Figures 2,3).

\section{Aspiration therapy}

The AspireAssist System is an FDA approved device that is a modified percutaneous gastrostomy (PEG) tube designed to remove approximately $30 \%$ of ingested meals. It is approved for a BMI range between 35 and $55 \mathrm{~kg} / \mathrm{m}^{2}$. The mechanisms behind weight loss are two-fold: removal of calories and decrease in food intake, with the former driving the majority of the weight loss. One open label randomized control trial showed 14\% TBWL at 12 months with aspiration therapy (AT) compared to $4.9 \%$ in controls. The most common adverse events were peristomal granulation tissue, post-operative abdominal pain, irritation at the tube site, and nausea, but $99 \%$ of these events were considered mild to moderate and managed conservatively (38). A post-market study that tracked 201 AT patients over 4 years showed mean TBWL of $18.2 \%, 19.8 \%, 21.3 \%$, and $19.2 \%$ at $1,2,3$, and 4 years, respectively, which suggests AT is durable and has good outcomes for long-term weight loss. It was also noted that there were significant decreases in HbAlc, triglycerides, blood pressure, and fasting blood glucose levels (39). Another study conducted a year later confirmed the results of the post-market study: 58 AT patients had steadily increasing TBWL of $14.2 \%, 15.3 \%, 16.6 \%$, and $18.7 \%$ at $1,2,3$, and 4 years, respectively (40). In both studies, side effects were minor, with most of them consisting of a similar type to that of traditional PEG tubes (Figure 4).

\section{Transoral outlet reduction (TORe)}

TORe was designed specifically for post-Roux-En-Y gastric bypass (RYGB) surgery patients with weight regain. It involves endoscopic suturing at the gastrojejunal anastomosis (GJA) site to reduce the size of the stomal opening. Normally after RYGB, the stomal opening is reduced to a small size, with a GJA of less than $10 \mathrm{~mm}$ as considered normal (42). By delaying the emptying of gastric contents, thereby preserving satiation, RYGB is 

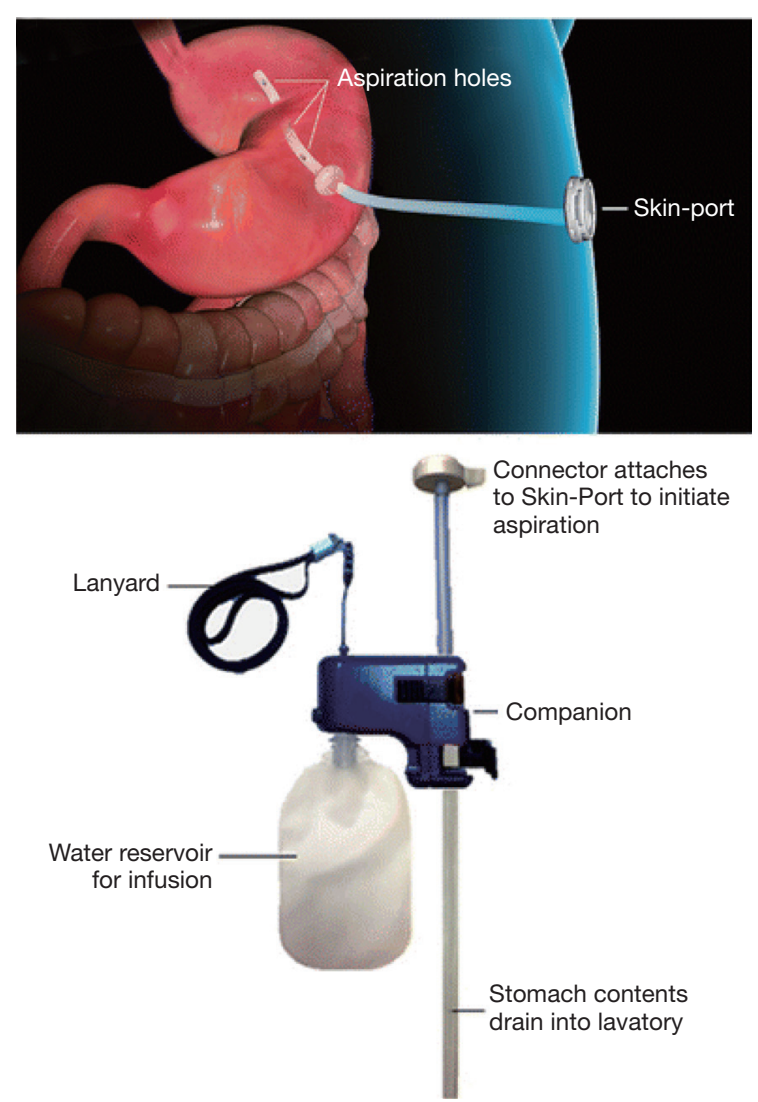

Figure 4 Aspiration therapy (41).

very effective at reducing weight initially, with statistics estimating an average EWL of $65-80 \%$ after $2-3$ years (43). However, over time the stoma often gradually dilates, which can result in weight regain. One long-term follow up study of 150 post-RYGB patients demonstrated that 8.6 years after surgery, the average GJA opening was $24.1 \mathrm{~mm}$, with an average weight regain of close to $50 \%$ of lost weight from RYGB (44). Thus, the intention of TORe is to re-reduce the size of the stomal opening. So far, three separate large group studies have shown the effectiveness of TORe, with an average weight loss of $7.8,8.5,10.5 \mathrm{~kg}$ at the 12 -month mark $(42,44,45)(46)$. One retrospective study of 70 patients from 2009 to 2018 showed specifically that patients with at least $85 \%$ stoma diameter reduction experienced significantly greater EWL. The most common side effects of this procedure were nausea, vomiting, constipation, and throat pain, with rare occurrences of bleeding and severe narrowing at the GJA aperture (47) (Figure 5).

\section{Primary obesity surgery endoluminal (POSE) (not FDA approved)}

POSE (USGI Medical, San Clemente, CA) uses the incisionless operating platform (IOP) to create full thickness gastric tissue plications along the fundus and distal body. The IOP consist of four ports, a combination of a grasper, a probe with helical tip, and a catheter system that delivers suture anchors. A prospective observational study of 147 patients demonstrated that POSE was well tolerated, had no serious adverse events, and at 12 months TBWL was $15.1 \%$ and EWL was $44.9 \%$ (48). The MILEPOST trial was a randomized multicenter study of 43 patients that compared POSE with lifestyle therapy $v s$. lifestyle therapy alone (49). In the POSE group, EWL and TBWL was 45.0 and $13.0 \%$, respectively, compared to $18.1 \%$ and $5.3 \%$ in the lifestyle modification group, respectively. The ESSENTIAL trial was a randomized sham-controlled trial of 332 patients that compared POSE to lifestyle modification. POSE participations demonstrated $4.9 \%$ TBWL vs. control of $1.38 \%$ TBWL (20). Major adverse events in the ESSENTIAL trial included bleeding, hepatic abscess, abdominal pain, nausea, and vomiting. Of note, immediately after POSE, delayed gastric emptying had been observed but normalizes after 6 months. Ghrelin and increased peptide $\mathrm{YY}$ has also been implicated in its efficacy (50). Additionally, the IOP has had FDA approval since 2006, however it is approved for indications other than bariatric surgery.

\section{Endoscopic sleeve gastroplasty (ESG) (FDA approved device, off label for obesity)}

ESG is a minimally invasive procedure that uses the Overstitch Endoscopic Suturing System (Apollo Endosurgery, Austin, TX). Full thickness sutures are placed along the greater curvature of the stomach through the gastric wall with the help of a helix device to capture tissue to create a sleeve shaped stomach. The Overstitch Device contains a needle driver, a suture anchor, and a handle to transfer the suture (51). Multiple case series have shown successful weight loss. TBWL of $17.6-19.0 \%$ at 12 months and EWL of $54 \%$ also at 12 months have been shown (51-54). A large study of 213 patients demonstrated TBWL of $18.7 \%$ at 24 months. The study also demonstrated improvement in T2DM, HTN, and hypertriglyceridemia (55). Major 


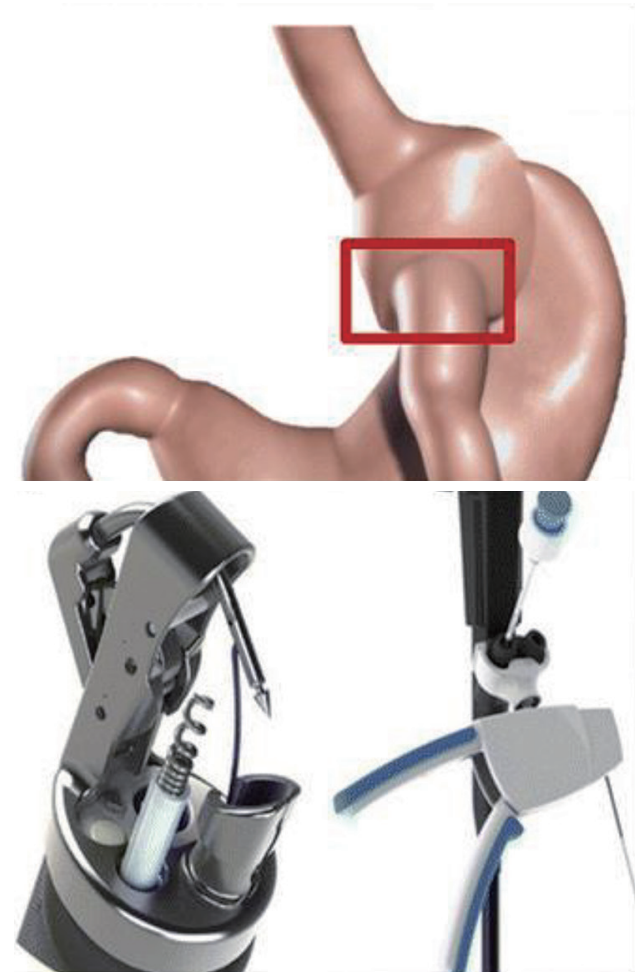

Figure 5 Transoral outlet reduction (44).

adverse events included abdominal pain and nausea in $20-80 \%$ of patients, and procedure related events were rare but included bleeding, pneumoperitoneum, and pulmonary embolism. A meta-analysis of 1,772 patients demonstrated clinically significant weight loss and a low rate of adverse events. At 6 months, mean TBWL was $15.1 \%$, decrease in BMI was $5.65 \mathrm{~kg} / \mathrm{m}^{2}$, and mean EWL was $57.7 \%$. Weight loss was sustained at 12 months and 24 months, mean TBWL $16.5 \%$ and $17.2 \%$, respectively. Severe adverse events rate was $2.2 \%$ and included pain requiring hospitalization, upper GI bleed, or peri-gastric leak (56). An international multicenter analysis of 193 patients reported sustained weight loss at 6 and 12 months. Mean TBWL was $14.25 \%$ and $15.06 \%$, respectively, and mean EWL as $56.15 \%$ and $59.41 \%$, respectively. Significant adverse event rate was $1.03 \%$ (57). A case series of 1,000 patients demonstrated that at 6,12 , and 18 months, mean \% TBWL was $13.7 \%, 15.0 \%$, and $14.8 \%$ respectively. Twenty four patients were readmitted for pain, procedure reversal, bleeding, or fever (58). A study of 1,600 patients demonstrated at 6,12 , and 18 months a mean \% TBWL was $15.8 \%, 17.1 \%, 17.3 \%$, respectively (59).

Additional studies have looked at ESG compared to

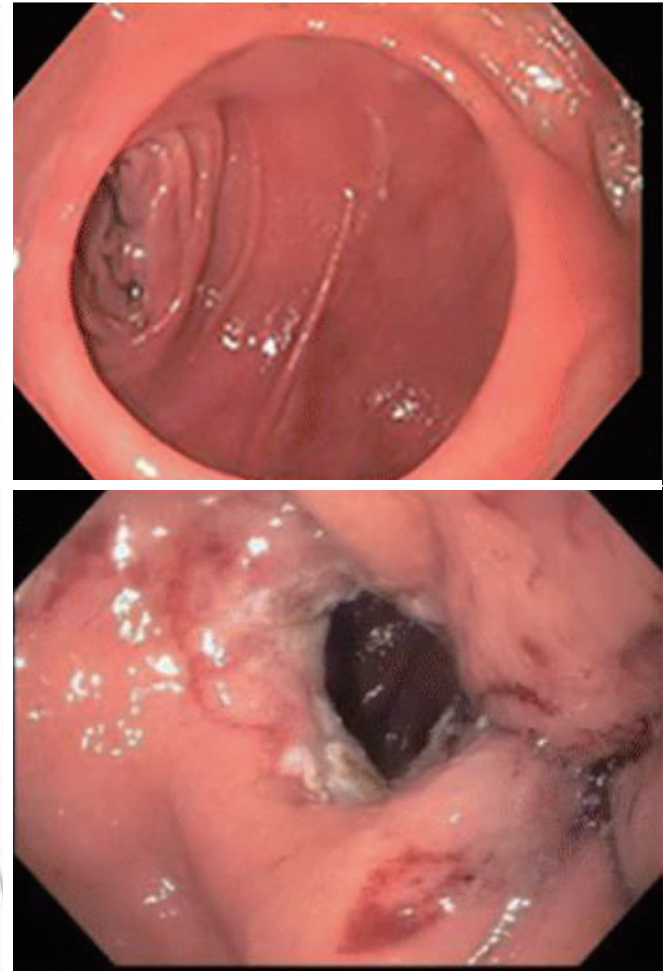

surgical weight loss procedures. A retrospective study compared 54 ESG patients with 83 matched laparoscopic sleeve gastrectomy (LSG) patients. At 1 and 6 months, mean \% TBWL in ESG patients was $9.8 \%$ and $17.1 \%$, respectively. For LSG, mean \% TBWL was $6.6 \%$ and $23.6 \%$, respectively. In patients with $\mathrm{BMI}<40 \mathrm{~kg} / \mathrm{m}^{2}$, $\%$ TBWL at 6 months was only slightly better for LSG than ESG groups, therefore ESG is a good option, particularly in this subset of patients, because most are not eligible for LSG. Although ESG had significantly less weight loss, there were lower adverse events, $5.2 \%$ vs. 16.9\% in LSG patients (60). There is a significant rate of post-LSG GERD which is not seen after ESG.

ESG has shown to be safe and effective in children and adolescents as well. A study of 109 children and adolescents in Saudi Arabia demonstrated mean \% TBWL at 6, 12, 18 , and 24 months was $14.4 \%, 16.2 \%, 15.4 \%$, and $13.7 \%$, respectively, with no significant morbidity or mortality (61) (Table 3, Figures 6, 7).

\section{Botox (FDA approved device, off label for obesity)}

Botulinum toxin is injected into the stomach wall and 
Table 3 Serious adverse events in ESG in 1,607 cases (59)

\begin{tabular}{lc}
\hline Adverse event & Events (\%) \\
\hline Intraabdominal collection & $7(0.4)$ \\
Hemorrhage requiring intervention & $6(0.4)$ \\
Refractory symptoms requiring reversal & $3(0.2)$ \\
Pneumoperitoneum/pneumothorax & $1(0.1)$ \\
Pulmonary embolism & $1(0.1)$ \\
Perforation or death & 0
\end{tabular}

ESG, endoscopic sleeve gastroplasty.
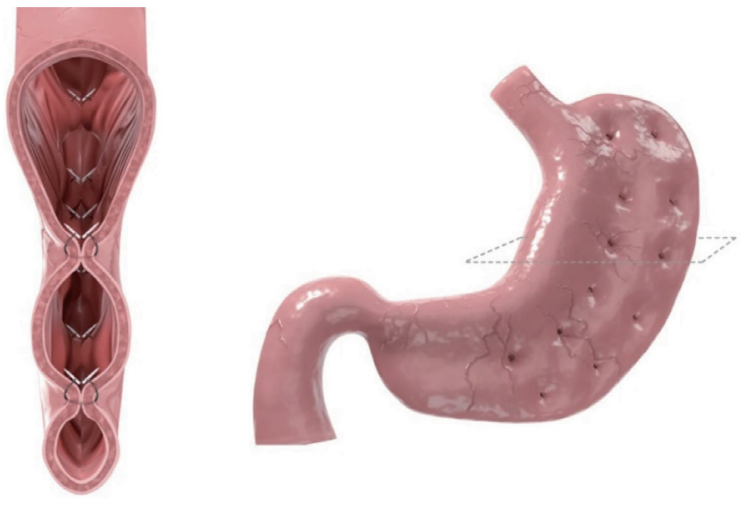

Figure 6 Cross sectional view (62).

delays gastric emptying and inhibits Ghrelin (64). There are a wide range of techniques. Five to 20 injections of $100-500$ IU of Botulinum Toxin A into the antrum is usually done. Randomized controlled trials are been mixed. A trial of 24 patients with 200 IU injections demonstrated statistically significant weight loss and delayed gastric emptying at 8 weeks (65). A double blinded RCT of 60 patients demonstrated significant difference in in gastric emptying after 2 weeks but no statistically significant weight loss at 16 weeks (66). Adverse events associated in this procedure are minimal, and include HTN, GERD, nausea. Because it is tolerated well without reported major complications, the procedure is a popular alternative to other endobariatric options.

\section{Small bowel interventions}

\section{Duodenal-jejunal bypass liner (not FDA approved)}

Endobarrier (GI Dynamics, Lexington, MA) is a duodenaljejunal bypass liner that functions as a malabsorptive device.
It anchors from the duodenal bulb to the proximal jejunum for 12 months. It is thought to potentiate blood sugar and gut hormones including ghrelin and glucagon like peptide 1 (67), however its mechanism is not completely understood. A 2015 meta-analysis of 11 RCTs demonstrated an EWL of $35.3 \%$ at 12 months vs. 9.4\% EWL in control group (68). The impact of EndoBarrier on Diabetes Mellitus is unclear as results are conflicting. A meta-analysis showing an improvement of $\mathrm{HbAlc}$ of $1.5 \%$ after 52 weeks and another reporting no significant reduction. Safety analysis of 71 implantations showed serious adverse events; migration in $4.9 \%$, GI bleed in $3.9 \%$, sleeve obstruction $3.4 \%$, and early device removal was in $18 \%$ (19). The FDA clinical trial, the ENDO trial, is on hold due to 7 cases of hepatic abscesses with an incidence of $3.5 \%$, surpassing the safety threshold of $2 \%(69)$.

\section{Gastroduodenojejunal bypass sleeve (GFBS) (not FDA approved)}

The GJBS (ValenTx, Inc., Maple Grove, MN) induces weight loss by mimicking RYGB via three mechanisms: food restriction, exclusion of food from stomach and small bowel, and exposure of undigested food to jejunum. It is placed at the GE junction and extends to proximal jejunum in a combined endoscopic and laparoscopic procedure. It is left in place for 12 months. The first clinical trial of 12 patients reported a 3-month EBWL of 39.5\% (70). A 12 -month trial of 12 patients revealed an EBWL of 35.9\%, however 4 patients also had partial cuff detachment (71).

\section{Duodenal mucosal resurfacing (DMR) (not FDA approved)}

The Revita DM (Fractyl Laboratories, Inc., Lexington, MA) uses a catheter to hydrothermally ablate the duodenal mucosa which results in improved glycemic control. The duodenal mucosa in T2DM patients is abnormally hypertrophied, and has hyperplasia of the enteroendocrine cells. Ablation allows for resetting of these cells. A non-randomized, single arm, proof of concept study was performed in 39 patients with T2DM (mean A1C 9\% and BMI $31 \mathrm{~kg} / \mathrm{m}^{2}$ ). Long and short ablations were performed at 9 or $3 \mathrm{~cm}$ in the duodenum (72), at 3 months A1C improved by $2.5 \%$ and $1.2 \%$ respectively, at 6 months A1C improved by $1.4 \%$ and $0.7 \%$ respectively. Of note, there was no correlation between magnitude of weight loss and glycemic improvement. An international multicenter open-label study of 46 patients reported mean $\mathrm{AlC}$ decreased $(-10 \pm 2 \mathrm{mmol} / \mathrm{mol})$, fasting 

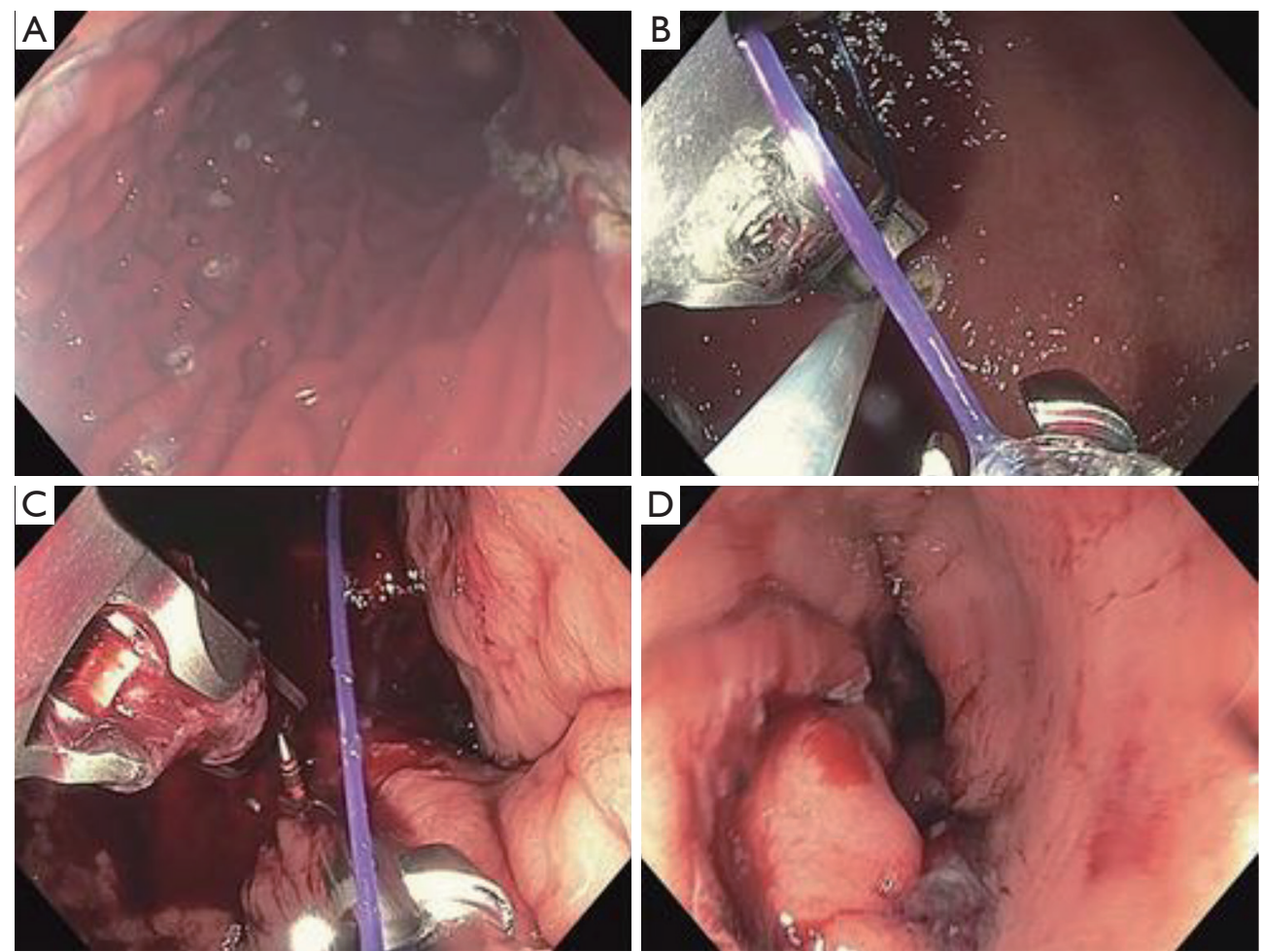

Figure 7 Endoscopic sleeve gastroplasty. (A) APC markings on anterior wall, greater curvature and posterior wall. (B) The tissue helix. (C) Release of the T-tag. (D) Gastric sleeve completed (63). APC, argon plasma coagulation.

glucose improved $(-1.7 \pm 0.5 \mathrm{mmol} / \mathrm{L})$, weight was modestly reduced $(-2.5 \mathrm{~kg})$, and HOMA-IR improved $(-2.9 \pm 1.1)$. Of the $52 \%$ that had at least one adverse event, $81 \%$ was of them were mild (73). The Revita-2 trial by Fractyl Laboratory examined DMR for T2DM patients with and without NAFLD. A 1.2\% reduction of HbA1c 24 weeks was demonstrated, and a $32 \%$ relative reduction in liver fat at 12 weeks was shown $(74,75)$.

\section{Self-assembling magnets (not FDA approved)}

The Incisionless Magnetic Anastamosis System (IMAS) (GI Windows, Inc., West Bridgewater MA) utilizes selfassembling octagonal magnets that are delivered into the terminal ileum and proximal jejunum via simultaneous colonoscopy and endoscopy to form an anastomosis. The anastomosis is larger than would otherwise be possible through solely endoscopic delivery. The magnets are then passed through the stool after several days, leaving a bypass from jejunum to ileum. The partial jejunoileal bypass diverts bile acids and nutrients into the ileum thus allowing for decreased absorption. A single arm pilot study showed that in 10 patients, the anastomosis was patent at 1 year with an average TBWL of $14.6 \%$ (40.2\% EWL at 12 months). Additionally, it showed reduction of A1C by $1.9 \%$ in four patients with T2DM and by $1.0 \%$ in three participants with prediabetes (71).

\section{Conclusions}

There currently exists a tremendous unmet need for obesity patients. Pharmacotherapy and lifestyle interventions have been shown to have only modest results. Bariatric surgery, though effective, remains inaccessible to many patients due to cost, complications, and invasive nature. In this review, we identified several endoscopic bariatric treatment options. They are minimally invasive, reversible, effective, cheaper, and safer for surgical candidates. Additional studies are needed on long term efficacy, outcomes of metabolic diseases, and head to head RCTs. However, the future of obesity medicine lies in a multidisciplinary approach that requires a combination of treatment strategies. 


\section{Acknowledgments}

Funding: None.

\section{Footnote}

Provenance and Peer Review: This article was commissioned by the Guest Editor (Amy Tyberg) for the series "Innovation in Endoscopy" published in Translational Gastroenterology and Hepatology. The article has undergone external peer review.

Conflicts of Interest: All authors have completed the ICMJE uniform disclosure form (available at https://tgh.amegroups. com/article/view/10.21037/tgh.2020.03.09/coif). The series "Innovation in Endoscopy" was commissioned by the editorial office without any funding or sponsorship. AS reports personal fees from Obalon, outside the submitted work. The authors have no other conflicts of interest to declare.

Ethical Statement: The authors are accountable for all aspects of the work in ensuring that questions related to the accuracy or integrity of any part of the work are appropriately investigated and resolved.

Open Access Statement: This is an Open Access article distributed in accordance with the Creative Commons Attribution-NonCommercial-NoDerivs 4.0 International License (CC BY-NC-ND 4.0), which permits the noncommercial replication and distribution of the article with the strict proviso that no changes or edits are made and the original work is properly cited (including links to both the formal publication through the relevant DOI and the license). See: https://creativecommons.org/licenses/by-nc-nd/4.0/.

\section{References}

1. Adams KF, Schatzkin A, Harris TB, et al. Overweight, obesity, and mortality in a large prospective cohort of persons 50 to 71 years old. N Engl J Med 2006;355:763-78.

2. Narayanaswami V, Dwoskin LP. Obesity: Current and potential pharmacotherapeutics and targets. Pharmacol Ther 2017;170:116-47.

3. Chang SH, Stoll CR, Song J, et al. The effectiveness and risks of bariatric surgery: an updated systematic review and meta-analysis, 2003-2012. JAMA Surg 2014;149:275-87.
4. Imbus JR, Voils CI, Funk LM. Bariatric surgery barriers: a review using Andersen's Model of Health Services Use. Surg Obes Relat Dis 2018;14:404-12.

5. Schulman AR, Thompson CC. Complications of Bariatric Surgery: What You Can Expect to See in Your GI Practice. Am J Gastroenterol 2017;112:1640-55.

6. Ma IT, Madura JA, 2nd. Gastrointestinal Complications After Bariatric Surgery. Gastroenterol Hepatol (N Y) 2015;11:526-35.

7. Ponce J, Woodman G, Swain J, et al. The REDUCE pivotal trial: a prospective, randomized controlled pivotal trial of a dual intragastric balloon for the treatment of obesity. Surg Obes Relat Dis 2015;11:874-81.

8. Agnihotri A, Xie A, Bartalos C, et al. Real-World Safety and Efficacy of Fluid-Filled Dual Intragastric Balloon for Weight Loss. Clin Gastroenterol Hepatol 2018;16:1081-8.e1.

9. Courcoulas A, Abu Dayyeh BK, Eaton L, et al. Intragastric balloon as an adjunct to lifestyle intervention: a randomized controlled trial. Int $\mathrm{J}$ Obes (Lond) 2017;41:427-33.

10. Vargas EJ, Pesta CM, Bali A, et al. Single Fluid-Filled Intragastric Balloon Safe and Effective for Inducing Weight Loss in a Real-World Population. Clin Gastroenterol Hepatol 2018;16:1073-80.e1.

11. Sullivan S, Swain J, Woodman G, et al. Randomized shamcontrolled trial of the 6-month swallowable gas-filled intragastric balloon system for weight loss. Surg Obes Relat Dis 2018;14:1876-89.

12. Moore RL, Seger MV, Garber SM, et al. Clinical safety and effectiveness of a swallowable gas-filled intragastric balloon system for weight loss: consecutively treated patients in the initial year of U.S. commercialization. Surg Obes Relat Dis 2019;15:417-23.

13. Machytka E, Gaur S, Chuttani R, et al. Elipse, the first procedureless gastric balloon for weight loss: a prospective, observational, open-label, multicenter study. Endoscopy 2017;49:154-60.

14. Genco A, Ernesti I, Ienca R, et al. Safety and Efficacy of a New Swallowable Intragastric Balloon Not Needing Endoscopy: Early Italian Experience. Obes Surg 2018;28:405-9.

15. Gomez V, Woodman G, Abu Dayyeh BK. Delayed gastric emptying as a proposed mechanism of action during intragastric balloon therapy: Results of a prospective study. Obesity (Silver Spring) 2016;24:1849-53.

16. Mathus-Vliegen EM, de Groot GH. Fasting and mealinduced CCK and PP secretion following intragastric 
balloon treatment for obesity. Obes Surg 2013;23:622-33.

17. Sullivan S, Edmundowicz SA, Thompson CC. Endoscopic Bariatric and Metabolic Therapies: New and Emerging Technologies. Gastroenterology 2017;152:1791-801.

18. Ribeiro da Silva J, Proenca L, Rodrigues A, et al. Intragastric Balloon for Obesity Treatment: Safety, Tolerance, and Efficacy. GE Port J Gastroenterol 2018;25:236-42.

19. Force ABET, Committee AT, Abu Dayyeh BK, et al. ASGE Bariatric Endoscopy Task Force systematic review and meta-analysis assessing the ASGE PIVI thresholds for adopting endoscopic bariatric therapies. Gastrointest Endosc 2015;82:425-38.e5.

20. Sullivan S, Swain JM, Woodman G, et al. Randomized sham-controlled trial evaluating efficacy and safety of endoscopic gastric plication for primary obesity: The ESSENTIAL trial. Obesity (Silver Spring) 2017;25:294-301.

21. Yorke E, Switzer NJ, Reso A, et al. Intragastric Balloon for Management of Severe Obesity: a Systematic Review. Obes Surg 2016;26:2248-54.

22. Turkeltaub JA, Edmundowicz SA. Endoscopic Bariatric Therapies: Intragastric Balloons, Tissue Apposition, and Aspiration Therapy. Curr Treat Options Gastroenterol 2019;17:187-201.

23. Tate CM, Geliebter A. Intragastric Balloon Treatment for Obesity: FDA Safety Updates. Adv Ther 2018;35:1-4.

24. Available online: https://www.fda.gov/medical-devices/ letters-health-care-providers/update-potential-risksliquid-filled-intragastric-balloons-letter-health-careproviders-0

25. Uyak D. Clinical study of a new/an adjustable intragastric balloon (SPATZ 3) with 110 patients (MEDICAL ONE HAMBURG/GERMANY). Gastrointest Endosc 2018;87:6S.

26. Russo T, Aprea G, Formisano C, et al. BioEnterics Intragastric Balloon (BIB) versus Spatz Adjustable Balloon System (ABS): Our experience in the elderly. Int J Surg 2017;38:138-40.

27. Machytka E, Klvana P, Kornbluth A, et al. Adjustable intragastric balloons: a 12-month pilot trial in endoscopic weight loss management. Obes Surg 2011;21:1499-507.

28. Brooks J, Srivastava ED, Mathus-Vliegen EM. One-year adjustable intragastric balloons: results in 73 consecutive patients in the U.K. Obes Surg 2014;24:813-9.

29. Alsabah S, Al Haddad E, Ekrouf S, et al. The safety and efficacy of the procedureless intragastric balloon. Surg Obes Relat Dis 2018;14:311-7.
30. Al-Subaie S, Khalifa S, Buhaimed W, et al. A prospective pilot study of the efficacy and safety of Elipse intragastric balloon: A single-center, single-surgeon experience. Int J Surg 2017;48:16-22.

31. Ashrafian H, Monnich M, Braby TS, et al. Intragastric balloon outcomes in super-obesity: a 16-year city center hospital series. Surg Obes Relat Dis 2018;14:1691-9.

32. Saruc M, Boler D, Karaarslan M, et al. Intragastric balloon treatment of obesity must be combined with bariatric surgery: a pilot study in Turkey. Turk J Gastroenterol 2010;21:333-7.

33. TransPyloric Shuttle/TransPyloric Shuttle Delivery Device. Available online: https://www.accessdata.fda.gov/ cdrh_docs/pdf18/P180024B.pdf

34. Transpyloric shuttle/ transpyloric shuttle delivery device instructions for use. Available online: https://www. accessdata.fda.gov/cdrh_docs/pdf18/P180024D.pdf

35. Lee PC, Dixon J. Medical devices for the treatment of obesity. Nat Rev Gastroenterol Hepatol 2017;14:553-64.

36. Available online: https://www.accessdata.fda.gov/cdrh_ docs/pdf18/P180024D.pdf

37. Available online: https://www.accessdata.fda.gov/cdrh_ docs/pdf18/P180024D.pdf

38. Thompson CC, Abu Dayyeh BK, Kushner R, et al. Percutaneous Gastrostomy Device for the Treatment of Class II and Class III Obesity: Results of a Randomized Controlled Trial. Am J Gastroenterol 2017;112:447-57.

39. Nystrom M, Machytka E, Noren E, et al. Aspiration Therapy As a Tool to Treat Obesity: 1- to 4-Year Results in a 201-Patient Multi-Center Post-Market European Registry Study. Obes Surg 2018;28:1860-8.

40. Thompson CC, Abu Dayyeh BK, Kushnir V, et al. Aspiration therapy for the treatment of obesity: 4-year results of a multicenter randomized controlled trial. Surg Obes Relat Dis 2019;15:1348-54.

41. Available online: https://media.springernature.com/ original/springer-static/image/art \%3A10.1007\%2 Fs11695-017-3096-5/MediaObjects/11695_2017_3096_ Fig1_HTML.gif

42. Vargas EJ, Bazerbachi F, Rizk M, et al. Transoral outlet reduction with full thickness endoscopic suturing for weight regain after gastric bypass: a large multicenter international experience and meta-analysis. Surg Endosc 2018;32:252-9.

43. Espinet Coll E, Nebreda Duran J, Lopez-Nava Breviere G, et al. Efficacy and safety of transoral outlet reduction via endoscopic suturing in patients with weight regain after a surgical Roux-en-Y gastric bypass. Rev Esp Enferm Dig 
2018;110:551-6.

44. Kumar N, Thompson CC. Transoral outlet reduction for weight regain after gastric bypass: long-term follow-up. Gastrointest Endosc 2016;83:776-9.

45. Callahan ZM, Su B, Kuchta K, et al. Five-year results of endoscopic gastrojejunostomy revision (transoral outlet reduction) for weight gain after gastric bypass. Surg Endosc 2020;34:2164-71.

46. Pajot G, Calderon G, Acosta A. Endoscopic Treatments for Obesity. Curr Treat Options Gastroenterol 2017;15:660-75.

47. Chablaney S, Kumta NA. Endoscopic bariatric and metabolic therapies: Another tool for the management of diabetes and obesity. J Diabetes 2019;11:351-8.

48. Lopez-Nava G, Bautista-Castano I, Jimenez A, et al. The Primary Obesity Surgery Endolumenal (POSE) procedure: one-year patient weight loss and safety outcomes. Surg Obes Relat Dis 2015;11:861-5.

49. Miller K, Turro R, Greve JW, et al. MILEPOST Multicenter Randomized Controlled Trial: 12-Month Weight Loss and Satiety Outcomes After pose (SM) vs. Medical Therapy. Obes Surg 2017;27:310-22.

50. Espinos JC, Turro R, Moragas G, et al. Gastrointestinal Physiological Changes and Their Relationship to Weight Loss Following the POSE Procedure. Obes Surg 2016;26:1081-9.

51. Abu Dayyeh BK, Neto MG, Lopez-Nava G, et al. Endoscopic sleeve gastroplasty is safe and effective: pitfalls of a flawed systematic review. Surg Obes Relat Dis 2019;15:1423-4.

52. Sharaiha RZ, Kumta NA, Saumoy M, et al. Endoscopic Sleeve Gastroplasty Significantly Reduces Body Mass Index and Metabolic Complications in Obese Patients. Clin Gastroenterol Hepatol 2017;15:504-10.

53. Lopez-Nava G, Galvao M, Bautista-Castano I, et al. Endoscopic sleeve gastroplasty with 1-year followup: factors predictive of success. Endosc Int Open 2016;4:E222-7.

54. Lopez-Nava G, Galvao MP, Bautista-Castano I, et al. Endoscopic Sleeve Gastroplasty: How I Do It? Obes Surg 2015;25:1534-8.

55. Lopez-Nava G, Sharaiha RZ, Vargas EJ, et al. Endoscopic Sleeve Gastroplasty for Obesity: a Multicenter Study of 248 Patients with 24 Months Follow-Up. Obes Surg 2017;27:2649-55.

56. Hedjoudje A, Dayyeh BA, Cheskin LJ, et al. Efficacy and Safety of Endoscopic Sleeve Gastroplasty: A Systematic Review and Meta-Analysis. Clin Gastroenterol Hepatol 2020;18:1043-53.e4.

57. Barrichello S, Hourneaux de Moura DT, Hourneaux de Moura EG, et al. Endoscopic sleeve gastroplasty in the management of overweight and obesity: an international multicenter study. Gastrointest Endosc 2019;90:770-80.

58. Alqahtani A, Al-Darwish A, Mahmoud AE, et al. Shortterm outcomes of endoscopic sleeve gastroplasty in 1000 consecutive patients. Gastrointest Endosc 2019;89:1132-8.

59. Storm AC, Abu Dayyeh BK. Endoscopic sleeve gastroplasty for obesity: defining the risk and reward after more than 1600 procedures. Gastrointest Endosc 2019;89:1139-40.

60. Fayad L, Adam A, Schweitzer M, et al. Endoscopic sleeve gastroplasty versus laparoscopic sleeve gastrectomy: a casematched study. Gastrointest Endosc 2019;89:782-8.

61. Alqahtani A, Elahmedi M, Alqahtani YA, et al. Endoscopic Sleeve Gastroplasty in 109 Consecutive Children and Adolescents With Obesity: Two-Year Outcomes of a New Modality. Am J Gastroenterol 2019;114:1857-62.

62. Shahnazarian V, Ramai D, Sarkar A. Endoscopic bariatric therapies for treating obesity: a learning curve for gastroenterologists. Transl Gastroenterol Hepatol 2019;4:16.

63. Badurdeen DS, Kumbhari V. Endoscopic sleeve gastroplasty and its application to China. J Dig Dis 2017;18:551-5.

64. Hill C, Khashab MA, Kalloo AN, et al. Endoluminal weight loss and metabolic therapies: current and future techniques. Ann N Y Acad Sci 2018;1411:36-52.

65. Foschi D, Corsi F, Lazzaroni M, et al. Treatment of morbid obesity by intraparietogastric administration of botulinum toxin: a randomized, double-blind, controlled study. Int J Obes (Lond) 2007;31:707-12.

66. Mittermair R, Keller C, Geibel J. Intragastric injection of botulinum toxin A for the treatment of obesity. Obes Surg 2007;17:732-6.

67. Vilarrasa N. EndoBarrier(R) in Grade I Obese Patients with Long-Standing Type 2 Diabetes: Role of Gastrointestinal Hormones in Glucose Metabolism. Obes Surg 2017;27:194-5.

68. Rohde U, Federspiel CA, Vilmann P, et al. The impact of EndoBarrier gastrointestinal liner in obese patients with normal glucose tolerance and in patients with type 2 diabetes. Diabetes Obes Metab 2017;19:189-99.

69. FDA. Available online: https://clinicaltrials.gov/ct2/show/ NCT01728116.

70. Espinet-Coll E, Nebreda-Duran J, Gomez-Valero JA, et al. Current endoscopic techniques in the treatment of 
obesity. Rev Esp Enferm Dig 2012;104:72-87.

71. Sandler BJ, Rumbaut R, Swain CP, et al. One-year human experience with a novel endoluminal, endoscopic gastric bypass sleeve for morbid obesity. Surg Endosc 2015;29:3298-303.

72. Rajagopalan $\mathrm{H}$, Cherrington $\mathrm{AD}$, Thompson CC, et al. Endoscopic Duodenal Mucosal Resurfacing for the Treatment of Type 2 Diabetes: 6-Month Interim Analysis From the First-in-Human Proof-of-Concept Study. Diabetes Care 2016;39:2254-61.

73. van Baar ACG, Holleman F, Crenier L, et al. Endoscopic

doi: 10.21037/tgh.2020.03.09

Cite this article as: Reja D, Zhang C, Sarkar A. Endoscopic bariatrics: current therapies and future directions. Transl Gastroenterol Hepatol 2022;7:21. duodenal mucosal resurfacing for the treatment of type 2 diabetes mellitus: one year results from the first international, open-label, prospective, multicentre study. Gut 2020;69:295-303.

74. Fractyl. Available online: https://www.fractyl.com/fractylannounces-revita-2-data-showing-revita-dmr-providesstatistically-significant-improvements-in-blood-glucoseand-liver-fat-in-type-2-diabetes-with-and-without-nafld/.

75. FDA. Available online: https://clinicaltrials.gov/ct2/show/ NCT03653091. 